\title{
No cabe la vida correcta en el mundo falso. Ética y política en Adorno
}

\author{
There is no right life in the wrong one. \\ Ethics and politics in Adorno
}

AGUSTÍN LUCAS PRESTIFILIPPO*

\begin{abstract}
Resumen: En este artículo analizamos la teoría crítica de la moral de Theodor Adorno. Para ello, estudiamos la revisión adorniana de los conceptos de la moral racional en dos pasos: primero, examinando las dificultades del conocimiento práctico situado en el contexto de las condiciones culturales del capitalismo tardío; luego, por medio de una indagación de estos obstáculos desde la perspectiva de la experiencia ética, esto es, desde el impulso de solidaridad que suscita el sufrimiento ajeno. Seguidamente, presentamos lo que Adorno denomina un límite ideológico de la moral para la reflexión y la práctica política orientada en un sentido emancipatorio.

Palabras clave: Theodor Adorno, ética, ideología, impulso de solidaridad, igualdad, política emancipatoria.
\end{abstract}

\begin{abstract}
In this paper we analyze Adorno's critical social theory of morality. In order to do that, we study the Adornian revision of the concepts of rational morality in two steps: first, by studying the difficulties of practical knowledge located in the context of socio-cultural conditions of late capitalism; then, by an inquiry into these obstacles from the perspective of the ethical experience, that is: from the solidarity impulse provoked by the suffering of others. Then, we present what Adorno understands as an ideological limit of morality for the reflection on political practice oriented in an emancipatory sense.
\end{abstract}

Key Words: Theodor Adorno, Ethics, Ideology, Impulse of Solidarity, Equality, Emancipatory Politics.

La cuestión del sufrimiento ajeno aparece en la teoría social de Adorno de una manera privilegiada en sus reflexiones ético-políticas. Ellas se rigen por la difícil pregunta de cómo, bajo las condiciones sociales del capitalismo tardío, es posible atender al dolor del otro sin desembocar en formas de conocimiento y de acción que integren ese dolor en un "sistema" -filosófico-moral o jurídico-político- que convierta, en sus efectos, la intención de realizar un acto de justicia en su contrario, esto es: en reproducción de la violencia.

El lugar en el que Adorno inscribe esta cuestión puede delimitarse a partir de un ejercicio de comparación con aquellos modelos filosóficos que cuestionan la tradición (universalista) del racionalismo moral. Adorno comparte con el cuestionamiento a la moral racional

Recibido: 17/02/2017. Aceptado: 02/09/2017.

* Doctor en Ciencias Sociales y Magíster en Estudios Literarios por la Universidad de Buenos Aires. Docente de esa misma casa de estudios e investigador del Instituto Gino Germani (UBA). Autor del libro El lenguaje del sufrimiento. Estética y política en la teoría social de Theodor Adorno (Prometeo), y de numerosos artículos en revistas especializadas en filosofía, teoría social y crítica cultural.alprestifilippo@gmail.com 
(Vernunftmoral) la interpretación del universalismo, de donde la filosofía moral extrae las garantías para un conocimiento y una acción en las capacidades que todos tenemos para una realización exitosa de lo bueno, como un medio de reproducción filosófica de modelos de conocimiento y de acción que refuerzan el "egoísmo" (Schopenhauer, 2009: § 67; Schmid Noerr, 1995: 13; Schweppenhäuser, 2006: 333) y la perspectiva "egológica” del yo (Levinas, 2002: 218; de Vries, 1989: 145 y ss.). El impasse del racionalismo moral, su recaída en el escepticismo - tal como se demuestra por medio del descubrimiento de la afinidad entre Kant y Sade (Adorno y Horkheimer, 1998)-, es lo que motiva a Adorno a cuestionar, para decirlo en términos hegelianos, sus abstracciones.

Sin embargo, Adorno se distancia del modo en que estas perspectivas cuestionan la "moral abstracta" desde una perspectiva puramente filosófica. Que ya no sea posible una vida correcta en un mundo falso (Es gibt kein richtiges Leben im falschen) significa para Adorno que cuando reflexionamos sobre los efectos subjetivos que las condiciones culturales de la sociedad capitalista produce en el problema de la posibilidad de la acción moral, se vuelve evidente la imposibilidad de una realización de los esfuerzos que podrían ponerla en práctica. En relación a la situación social del capitalismo tardío que impide la realización práctica de la idea de una moral "auto-evidente" Adorno sostiene que, en este contexto, "cada acción importante cuya teoría uno procura desarrollar tiene la tendencia desafortunada, incluso fatal, a conducirnos a pensar de una manera en la que entramos en conflicto con nosotros mismos" (Adorno, 1963: 15).

Para dar cuenta de esta paradoja presentada en la perspectiva de primera persona, Adorno sitúa este problema en una reflexión crítica que vuelve comprensibles las razones sociales de la dialéctica negativa de lo bueno; esto es, de los motivos sociales que explican la "tendencia desafortunada, incluso fatal" de la inversión de las acciones que pretenden obrar moralmente (Wishke, 1993). Su perspectiva crítica de la moral no solamente cuestiona los modos dominantes de interpretar la relación entre el individuo y los demás, sino también se cuestiona a sí misma como perspectiva en primera persona, requiriendo una articulación conceptual de la reflexión ética con una perspectiva teórica que sea capaz de reflexionar sobre una política emancipatoria (Morris, 2001: 144).

Para analizar la revisión adorniana de los conceptos de la moral racional, procedemos en cuatro pasos: 1) examinamos las dificultades del conocimiento práctico situado en el contexto de las condiciones culturales del capitalismo tardío; 2) indagamos en estos obstáculos desde la perspectiva de la experiencia ética, esto es, desde el impulso de solidaridad que suscita el sufrimiento ajeno; 3) luego, presentamos lo que Adorno denomina un límite ideológico de la moral para la reflexión y la práctica política orientada en un sentido emancipatorio; y 4) finalmente, extraemos algunas conclusiones acerca del vínculo entre las reflexiones éticas y las reflexiones políticas en la teoría social de Adorno.

\section{El conocimiento práctico en el capitalismo tardío}

Adorno entiende por moral racional la concepción filosófica que define el valor de lo bueno como el resultado de un juicio basado en razones que pueden ser contrastadas y evaluadas en un procedimiento de examen reflexivo. Esta reflexión garantiza que un juicio acerca de qué hacer para actuar moralmente no se fundamente en motivos que procedan de 
las "inclinaciones" del sujeto que juzga. En esto se basa la universalidad de la razón práctica libre de inclinaciones: es aquello que justifica mi juicio como "puro", esto es, como razón suficiente para actuar. En este sentido, mi juicio adquiere el atributo de moral en la medida en que acepte como un motivo legítimo de mi acción aquella máxima que los demás puedan aceptar también como una razón legítima.

La moral racional, que para Adorno se expresa plenamente en la formulación kantiana, oblitera la posibilidad de pensar en conjunto al problema del conocimiento moral y al problema de la acción ética concreta, y esto se puede explicar por el énfasis hiperbólico que la moral racional coloca en la convicción (Gesinnung) de las acciones, cuyas intenciones aparecen como excluyentemente relevantes frente a la evaluación de sus efectos, "porque cuando se trata del valor moral no importan las acciones, que se ven, sino aquellos íntimos principios de las mismas, que no se ven" (Kant, 2013a: 32).

No es la primera vez que este modelo filosófico de lo bueno suscita objeciones. Podría reconstruirse toda una tradición que incluye a autores tan distintos como Schiller y Hegel, o Nietzsche y Foucault. Como ellos, también Adorno cuestiona la fundamentación racional de la moral a partir de las consecuencias que ésta tiene para la realidad efectiva de los agentes. Adorno caracteriza a la abstracción que opera esta concepción de la reflexión ética con los términos de desobjetualización (Entgegenständlichung) y despractización (Entpraktizierung) (Adorno, 2005: 221). La moral racional "desobjetualiza" su objeto -la acción- cuando expulsa de su recinto aquello que la vuelve posible, es decir, "todo aquello que no soy yo en el sentido de ser mi propia razón" (Adorno, 1963: 106). La moral racional tiene vedada la posibilidad de concebir al momento de la aplicación de la ley sin incluir en su cadena de razonamientos un "salto" injustificable según la lógica intelectual: puesto que la moral racional sólo refiere los juicios morales a normas que los harían legítimos o justificables deductivamente, no puede incluir como filosóficamente significativo el pasaje hacia la decisión que realiza la acción. En este sentido, la moral racional "despractiza" la acción (Mentz, 2012).

Cuando Adorno (2003: 165) interpreta que esta abstracción es el efecto filosófico del rechazo de la "primacía del objeto" (Vorrang des Obekts), muestra que su teoría social persiste en rescatar al valor de lo bueno de las consecuencias escépticas en las que, según su perspectiva, desemboca la fundamentación racionalista. La teoría crítica de la moral parte de la exigencia de reflexionar sobre las relaciones que hacen a su materialidad efectiva. Esto supone que lo bueno no puede desgajarse de los medios que buscan realizarlo. Según la fundamentación racionalista de lo moralmente bueno, "la acción (Handlung) debe proceder directamente de mi representación (Vorstellung) y debe ser independiente de cualquier material al que esté ligada” (Adorno, 1963: 106). ¿Es posible pensar a la estructura de la acción ética en otros términos?

Puesto que la acción "debe ser independiente de cualquier material al que esté ligada", el momento de justificación de la ley no encuentra elementos que hagan posible una comprensión racional de la aplicación. La aplicación, esto es: la realización de la acción que ejecuta la ley, se le aparece a la moral racional como una "especie de cesura" (eine Art von Zäsur)" (Adorno, 1963: 79). Para esta concepción el momento de la acción implica un corte entre su resultado y los propósitos fundados en el examen introspectivo de las exigencias normativas. Según el cuestionamiento de Adorno, el hecho básico de la moral racional, la 
obediencia al mandato, depende de un presupuesto indemostrable. La moral racional atribuye al sujeto la posibilidad (Möglichkeit) de actuar tal como se le requiere por el mandato de la ley. Ahora bien, este presupuesto parte de una motivación optimista cuya base consiste en dar por hecho la identidad entre ambas instancias, la objetividad de la ley y la obediencia subjetiva, aun cuando se reconozcan ejemplos que la desmienten (Kant, 2013b: 128, 136).

Ante este optimismo, Adorno reconoce un "límite de la razón al interior de lo moral" (Adorno, 1963: 145) que bloquea pensar la posibilidad de una contradicción entre conocimiento de la ley y acción efectiva en el mundo social. Podríamos entender esto como la posibilidad del absurdo (Möglichkeit des Absurden) de la acción (Adorno, 1963: 144). Este elemento absurdo contenido en la posibilidad de la acción es interpretado por la moral racional como un elemento restrictivo. El hecho de que el agente no sepa a priori, dada cierta circunstancia, si logrará realizar en el "reino de la sensibilidad" sus propósitos morales sin que interfieran efectos que los desestabilicen, hace de este desconocimiento una amenaza que pone en riesgo los límites de la razón práctica. La moral racional oscila de esta manera entre la ingenuidad del optimismo y el escepticismo.

El modo en que Adorno responde a esta doble deriva de la ética de la convicción es interpretando la estructura del conocimiento que el individuo necesita en las situaciones concretas en las que tiene que actuar, esto es: el conocimiento situado, contextual, que precede a la acción, como significativa para el valor de lo bueno ( $C f r$. Bernstein, 2001). A diferencia del "paradigma deductivo" del juicio que exige la moral racional, que no logra aplicarse por el abismo que lo separa de la acción concreta, el conocimiento contextual es entendido por Adorno, de un modo similar al concepto neo-aristotélico de virtud, ${ }^{1}$ de manera tal que éste no desemboca en la dicotomía racionalista entre justificación y aplicación, conocimiento y acción.

Este modo situado del conocimiento práctico es precisado por Adorno en sus reflexiones sobre el problema ético-político de la decisión. La decisión es para Adorno una forma mínima de conocimiento que se adecúa a los requerimientos de la situación concreta. Esto significa que la decisión moral tampoco es un elemento racional, en el sentido estricto en que la filosofía entiende este atributo (Kant, 2013b: 154 y 55). La decisión es un factor "necesario para la práctica que no puede ser completamente explicado por la teoría" (Adorno, 1963: 10). Es una forma de conocimiento que hace posible una "reacción activa a las situaciones particulares" (Adorno, 1963: Ibíd.). En la decisión de un sujeto que actúa "toda otra consideración debe quedar subordinada" (Ibíd.) a un aspecto de la situación que se presenta con urgencia. Pero esta subordinación no puede ser entendida como el resultado de un "silogismo práctico".

El desplazamiento desde una fundamentación racionalista de la moral hacia una concepción situada del conocimiento que la acción ética requiere, permite entender el significado de la decisión ya no como una amenaza que acecha la posibilidad de lo bueno, sino como la interrupción inevitable de la lógica deductiva entre ley y razonamientos particulares. La cesura no es una fuerza exterior a lo moral que intercede entre el conocimiento y la acción volviendo imposible a lo bueno, sino que es el resultado de la percepción de un aconteci-

1 McDowell define a la virtud como la "habilidad de reconocer exigencias que las situaciones le imponen al comportamiento propio" (2001: 53). 
miento que exige una decisión. Para entender el tipo de conocimiento que la decisión es, Adorno introduce el ejemplo de "un refugiado que toca la puerta y pide asilo":

¿Cuál sería la consecuencia si se pusiera en acción la maquinaria de la consideración (Erwägungen) en lugar de simplemente actuar y decirse a sí mismo que aquí está un refugiado que puede ser asesinado por un Estado policial de un país, y que mi deber es por lo tanto esconderlo y protegerlo, y que por lo tanto cualquier otra consideración debe quedar subordinada a esto? Si la razón se ubicara aquí en un lugar incorrecto, entonces la razón devendría irracional (Ibíd.: 144-145).

Que la decisión se libere de "la maquinaria de la consideración", significa que ella es “espontánea” (Ibíd.: 9). La acción no necesita más argumentos que la misma evidencia del aspecto percibido en una situación como éticamente significativo. Pero esa percepción no es neutral. Compromete al sujeto en una implicación de la que no puede desentenderse. En este sentido, el conocimiento práctico que no se adecua al concepto racionalista es "impulsivo". La percepción de que alguien está siendo torturado o de que un refugiado sufre de persecución es suficiente motivo para saber que esto no debería suceder y que algo tiene que hacerse al respecto. En este sentido puede entenderse la afirmación de Derrida de que "una teoría del sujeto es incapaz de dar cuenta de la menor decisión" (1998: 87). La "actividad" de decidir se encuentra tensionada desde el comienzo por una impulsividad del que decide, la cual es motivada por la percepción de un otro necesitado. El impulso de la decisión no puede ser pensado por fuera de esta experiencia de una implicación del sujeto en las necesidades del otro; vale decir, la impulsividad de la decisión no exonera al sujeto de la responsabilidad, sino que, por el contrario, la refuerza de una manera que impide la "maquinaria de la consideración". La decisión, dice Derrida, "significa lo otro en mí, que decide y desgarra. La decisión pasiva, condición del acontecimiento, es siempre en mí, estructuralmente, otra decisión, una decisión desgarradora como decisión del otro. Del otro absoluto en mí, del otro como lo absoluto que decide de mí en mí (Ibíd.).

Sin embargo, sería un error entender este cuestionamiento como el comienzo de una nueva fundamentación filosófica, ahora adoptando al concepto de la decisión como principio. Si así fuera, recaería en el falso presupuesto de que es posible actuar de manera virtuosa en cualquier lugar y en cualquier momento. A la luz de la crítica adorniana de las abstracciones de la filosofía moral, es posible reconocer un secreto acuerdo entre el intelectualismo de la moral racional y el realismo del concepto neo-aristotélico de virtud; a saber: una confianza infundada en las capacidades del sujeto para realizar de manera lograda lo bueno en cualquier contexto. Según Adorno, desde el instante en que reducimos los problemas de la reflexión ética al problema "de la decisión de cada individuo", sacamos a éste "de su contexto, al individuo de la sociedad" (Adorno, 2005: 201). Por lo tanto, la abstracción que supone el concepto aislado de decisión "obedece al engaño del puro ser-en-sí absoluto: una limitada experiencia subjetiva usurpa la dignidad de lo más cierto de todo" (Ibíd.).

Frente a esta descontextualización en la que pueden recaer también las críticas realistas del intelectualismo ético, Adorno responde inscribiendo la cuestión de la decisión en un marco histórico específico. Esa marca histórica, aunque no la única, se da en la pregunta 
de si acaso la moral no "se ha vuelto obsoleta": "Fue Valéry quien expresó esto tal vez de la manera más sucinta con la formulación de la pregunta «¿Está envejeciendo la moral?»" (Adorno, 1963: 146). Esta referencia al carácter obsoleto de la pregunta por lo bueno apunta a la tesis de que el conocimiento que requiere la acción virtuosa es incapaz estructuralmente de adecuarse a las demandas que las sociedades les imponen a los agentes. Aquello de la decisión que queda desbordado por las sociedades modernas son las mismas condiciones del conocimiento situado de la acción que Adorno ha determinado contra la moral racional. La contraposición de un conocimiento práctico entendido como un acceso específico a la situación particular presupone que ésta puede ser conocida unívocamente. Es esta presuposición la que según el diagnóstico social de Adorno no es posible bajo las condiciones de la cultura moderna del capitalismo: dado que las situaciones presentan una opacidad al conocimiento práctico, la acción en la coyuntura del capitalismo tardío se ha vuelto si no imposible, sí radicalmente difícil. A esta dificultad alude la famosa afirmación adorniana de que en un mundo falso no es posible saber qué significa una vida buena. ${ }^{2}$

Adorno explica esta contradicción entre la acción ética y las condiciones culturales que impone las sociedades modernas en los términos generales de una tensión entre la homogeneidad entre situación y acción -que lo bueno requiere- y la complejidad social desbordante. De acuerdo con esto, el conocimiento práctico presupone una "sociedad relativamente homogénea"; por lo tanto, parecería que la acción sólo es posible en un "universo restringido": "Mirando hacia atrás, la positividad de lo bueno, la infalibilidad que los idealistas subjetivos le acreditaron, se desvela como función de una sociedad todavía en cierta medida cerrada, o al menos de su apariencia para la conciencia en ella confinada". (Adorno, 2005: 227). En este sentido, la acción ética se confronta con "la expansión contemporánea del universo que es al mismo tiempo inconmensurable con nuestra experiencia" (Ibid.). Este contexto socialmente desbordante exige una reflexión que es incompatible con la epistemología práctica de la decisión, puesto que da cuenta de la "indecibilidad" de las situaciones, o, de por qué el conocimiento práctico no puede garantizar de manera infalible la realización de una acción éticamente correcta (Adorno, 2005: 263).

La "divergencia entre comprensión y obrar" que instala la complejidad desbordante de la cultura capitalista; vale decir, la limitación de la posibilidad del individuo de hacer ejercicio de su virtud, la podemos entender como consecuencia del proceso de diferenciación social que inaugura el advenimiento de la cultura moderna del capitalismo: "Cuanto más se convierte en un ente para sí y se distancia de la armonía sin fisuras con el orden previamente dado, tanto menos son una sola cosa acto y conciencia" (Adorno, 1963: 214). La "irreconciliación de lo particular y lo universal" que eleva a principio la cultura capitalista hace que "la apelación a cualquiera de ellos" suponga "una injusticia para el opuesto" (Adorno, 2005: 221).

Esta diferenciación produce por lo tanto modificaciones estructurales en el modo en que el individuo se relaciona con la sociedad, que la teoría social crítica de Adorno se ocupa de analizar en sus distintos aspectos contradictorios. Puesto que, si este proceso

2 Aquí no analizamos la otra inscripción histórica que marca las reflexiones ético-políticas de Adorno, a saber: si es posible trazar, y si es así cómo, una línea de continuidad entre la moral racional y el sadismo de los verdugos de Auschwitz. Si bien esta otra inscripción se encuentra íntimamente relacionada con la que en este trabajo analizamos, posee una especificidad en su formulación que exige un desarrollo ulterior (Cfr. Adorno, 2005: 264). 
puede describirse en los términos de una "real separación" del individuo y la sociedad que deja en el pasado "la armonía sin fisuras" con la que se interpretaba el "orden previamente dado" (Ibíd.: 206), cabe observar también una mayor integración normativa de los individuos en la totalidad social, facilitada por los aparatos de la industria cultural. Mientras que el proceso de racionalización trae consigo "el proceso de emancipación del individuo" (Ibíd.: 243), este proceso es, al mismo tiempo, el proceso que conduce a la normalización del "mundo administrado" y que, también, promueve la interpretación de aquella emancipación según el modelo de la "ideología liberal” (Ibíd:: 206). En el capitalismo, es la "sociedad" la que "anima a los individuos a hipostasiar su propia individualidad y, por tanto, su libertad" (Ibíd.: 208). En este sentido puede interpretarse al concepto de autonomía de la voluntad sobre el que descansa la moral racional como la abstracción de un sujeto cuya identidad es forjada antes de su puesta en vínculo, con los otros y consigo mismo. La "ideología liberal” fomenta el "carácter mítico del puro ego, su nulidad" (Ibíd.: 218): "Lo que se presenta como entidad originaria, como mónada, es sólo el resultado de un aislamiento social del proceso social. Precisamente como absoluto es el individuo mera forma refleja de las relaciones de propiedad" (Adorno, 1998: 154). Mientras que "el individuo se siente libre en la medida en que se ha opuesto a la sociedad", su emancipación "termina en su abolición mediante la integración. Lo que produjo la libertad se invierte en no-libertad" (Adorno, 2005: 243).

La consecuencia evidente del proceso de pluralización de valores al que se asiste en las sociedades diferenciadas es la ausencia de criterios estables para distinguir con seguridad siempre y en cualquier lugar una acción éticamente correcta. Lo que puede ser bueno desde una perspectiva puede ser falso para la otra y viceversa ( $C f r$. Taylor, 1985). Las condiciones culturales de las sociedades modernas capitalistas someten al conocimiento y a la acción ética de los individuos a una lógica trágica de inversión de los valores: "la acción correcta aquí y ahora no es inmediatamente idéntica con lo que es bueno para la especie como un todo" (Adorno, 1963: 211).

Con esta inscripción de lo bueno en el contexto de las condiciones culturales que lo dificultan, Adorno apunta al hecho de que el logro de una acción depende no solamente de las capacidades y habilidades del sujeto para decidir, sino sobre todo de condiciones sobre las cuales el sujeto no posee control alguno: "Cuanto más implacablemente se comporte hasta en la más insignificante situación la sociedad de manera objetivo-antagonista, tanto menos garantizada como la correcta está cualquier decisión individual” (Adorno, 2005: 226). Eso implica que la reflexión ética se encuentra atada a una "falibilidad" que vuelve imposible toda seguridad acerca del vínculo entre conocimiento y acción: "El sujeto individual que se figura moralmente seguro fracasa y se convierte en cómplice" (Ibíd.).

Sin embargo, a diferencia del optimismo compartido por la fundamentación racional de la moral y por la ética de la virtud, el hecho de saber que toda decisión que intente actuar correctamente, en el curso de su realización, puede invertirse en su opuesto, esto es, saber que las condiciones culturales en las que se desarrollan las pretensiones de actuar condicionan al sujeto a una tensión de evaluaciones entre perspectivas en conflicto, no figura en la concepción de Adorno como un motivo para la exoneración. 


\section{Antinomias de la experiencia ética}

La presentación de este conflicto práctico de la vida social es incompleta si no atiende a los efectos que produce en la experiencia del agente. Adorno describe esos efectos, fundamentalmente en el "modelo" dedicado al concepto kantiano de libertad en Dialéctica negativa, a modo de una antinomia de la razón práctica. La crítica de la moral racional descubre el vínculo constitutivo de la acción con su otro. El afuera interno a lo bueno sobredetermina las acciones de un modo que excede el recinto delimitado de la moral abstracta: "Las acciones humanas siempre son acciones conscientes. (...) Pero la praxis necesita también de otra cosa (eines Anderen) (...), corporal (Leibhaften), mediado en la razón y cualitativamente distinto a ésta" (Adorno, 2005: 228). Esa otra cosa es llamada, no sin cierta dificultad, impulso somático (Cfr. Düttmann, 2004). ${ }^{3}$ Según Adorno, el impulso adquiere para la moral racional el estatuto de suplemento, un añadido (Hinzutretende) a la acción que contradice su apariencia de exterioridad simple. Lo añadido "desmiente el dualismo" (Ibíd:: 214). Este suplemento que se añade al pensamiento es "a la vez intramental y somático, empuja más allá de la esfera de la consciencia, a la cual sin embargo también pertenece" (Ibíd.).

Si se interpreta al impulso como una instancia de espontaneidad que libera al sujeto de las obligaciones que supone el examen introspectivo de la norma, se puede recaer en un decisionismo "que elimina a la razón en la transición a la acción" para luego entregar a la razón "al automatismo de la dominación; la libertad irreflexiva que éste se arroga se convierte en esclava de la total no-libertad" (Ibíd.: 215). La relación entre la acción consciente y el tipo de conocimiento que el impulso es, debe ser comprendida en un sentido genealógico: como "rudimento de una fase en la que el dualismo entre lo extramental y lo intramental aún no estaba fijado por completo" (Ibíd.: 214). En este sentido, "la misma consciencia pura -«la lógica»- es algo devenido y algo válido en lo que su propia génesis ha desaparecido" (Ibíd.). La rememoración (Eingedenken) de la acción de sus presupuestos olvidados por la fundamentación racionalista de la moral no puede aparecer entonces como la disolución de la validez en su génesis "extramental", sino que es una forma de la reflexión inmanente a la acción en la que esos presupuestos olvidados aparecen a la conciencia, transformándola. En la "inmediatez" del impulso somático -que Adorno ejemplifica a partir de las prácticas del amar y del acto de regalar-, la acción "impermeabilizada contra sí misma" recuerda su génesis en el proceso de exclusión del impulso, sin cuya eficacia la acción ética no sería posible.

Por lo tanto, el impulso figura como una fuente genuina de vínculos éticos, expresando la prelación del otro en la constitución del yo. En las reflexiones de Adorno, las acciones que nacen de esta exterioridad inmanente al agente son las que hacen posible las prácticas éticamente significativas. Sin embargo, ella aparece con motivo del encuentro con un otro padeciente, quien activa una suerte de "imitación": "Lo humano se aferra a la imitación: un hombre se hace verdaderamente hombre sólo cuando imita a otros hombres" (Adorno, 1998: 154). Vale decir, es porque nos "identificamos" con el sufrimiento ajeno que podemos reconocer aquella dimensión de ajenidad constitutiva en nosotros mismos. En este sentido,

3 "Una tarea de la teoría de la moral es limitar la propia perspectiva de la teoría; en otras palabras: mostrar que la esfera de la acción moral incluye algo que no puede ser descripto exhaustivamente en términos intelectuales, pero que tampoco debería ser transformado en un absoluto. (...) me resulta extraordinariamente difícil encontrar las palabras para describir este momento" (Adorno, 1963: 18). 
la teoría social de Adorno intenta "dislocar al sujeto como fundamento de la ética a los fines de ubicar al sujeto como problema de la ética" (Butler, 2005: 110). La interrogación ética consistiría de esta manera no tanto en la conformidad del sujeto con un determinado ethos colectivo, sino en el movimiento de reflexión entre la acción y la constitución del sujeto allí donde la apariencia de universalidad de un ethos específico queda desmentido, evidenciando su particularidad. Así como el sujeto que actúa impulsivamente ante la evidencia del sufrimiento ajeno se hace responsable por el otro, así también, al hacerlo, el sujeto que actúa se ve obligado a reflexionar sobre sí, sobre lo que Adorno denomina "la no-identidad del sujeto consigo mismo" (Adorno, 2005: 275). Hacer del sujeto un problema de la reflexión ética es indagar, como sostiene Butler en su lectura de las reflexiones éticas de Adorno, en "cómo las normas que gobiernan los principios éticos deben ser entendidos como operando no solamente para guiar la acción sino para decidir la cuestión de quién y qué es un sujeto" (Butler, 2005: Ibíd.).

El sentido preciso de esta reflexión sobre el sujeto que el impulso mimético hace posible requiere de mayores precisiones. Su contenido ético está orientado al respeto de aquello que en el otro no puede reducirse sin violencia al principio abstracto de la equivalencia. Según el diagnóstico de Adorno - compartido con Marx, Weber y Lukács-, el principio de equivalencia viabiliza las relaciones sociales en el mercado, pero también lo hace en otras instancias de la "superestructura" capitalista, sin las que el mercado no sería pensable. En el derecho civil, por ejemplo, se expresa en la figura del contrato como instancia de vínculo entre partes, y en la de persona jurídica para aludir al sujeto. Así, pues, el derecho moderno, "en cuanto instancia social de control", es acaso uno de los ámbitos sociales en donde la objetividad de la forma mercancía se ha expandido de la manera más clara violentando las identidades y las relaciones sociales:

En él se convierte en norma el principio formal de equivalencia, mide a todos por la misma vara. Tal igualdad, en la que desaparecen las diferencias, ayuda en secreto a encubrir la desigualdad. (...) Mediante las sanciones del derecho en cuanto instancia social de control (als gesellschaftlicher Kontrollinstanz), este recinto, ideológico en sí mismo, ejerce, plenamente en el mundo administrado, una violencia real (Adorno, 2005: 285$){ }^{4}$

Por el contrario, las formas de sociabilidad que destaca Adorno contradicen la lógica de aquellas instituciones y prácticas en las que el ejercicio del poder opera como medio de sometimiento. Ellas son acciones que exceden "la celda aislada de la pura interioridad", puesto que reconocen "aquellas cualidades insustituibles" que hacen al "calor de las cosas" (Adorno, 1998: 47). En tanto tales, adquieren el sentido de una apertura frente a la vulnerabilidad del otro, pues suponen una generosidad que suspende el primado de los propios intereses. El tipo de relaciones que inauguran estas actitudes se lesionan "con el valor que el propio yo se adjudica" (Ibíd:: 189), dado que la autoafirmación del sujeto contradice

4 Esa violencia, real, no desaparece incluso allí donde la equivalencia jurídica incluye una política dirigida a las diferencias, pues también en este caso puede producirse el efecto paradojal de "encerrar" a aquellos que sufren de una subordinación en una identidad definida exclusivamente por esa posición, reproduciendo el estigma y fortaleciendo así su sometimiento. (Cfr. Brown, 2002: 423). 
su apertura a las necesidades del otro. En la medida en que son ajenos a la mediación del cálculo y el interés individual, los comportamientos motivados en los impulsos somáticos escapan al proceso de abstracción al que los somete el principio de la equivalencia, haciendo posibles vínculos "involuntarios".

Sin embargo, sostiene Adorno paradójicamente, el momento de inmediatez del impulso es “mediado en la razón”. Al habilitar así el reconocimiento de la ajenidad del otro, la acción no puede denegar de la diferencia entre la petición de justicia contenida en el sufrimiento ajeno y el ensayo de respuesta que pretende disolverlo. Esa diferencia reconocida es lo que permite sostener que las acciones que recuerdan el impulso que las originan no aspiran a una empatía ingenua, sino "a la disolución de toda apariencia de inmediatez" (Ibíd.: 224). Adorno clarifica esto a partir de la ambigüedad que presenta el sufrimiento ajeno. Por un lado, el sufrimiento del otro exige ser disuelto por una acción ética que lo atienda: "El dolor habla: cesa" (Adorno, 2005: 191). Por otro, presenta una irreductible dimensión física que se resiste a ser incluida en cualquier esquema de sentido (Ibíd.). El sufrimiento físico del otro aparece así como un objeto cuyo reclamo es el más urgente de atender y, al mismo tiempo, el más difícil, por un reconocimiento no violento:

Sólo con el reconocimiento de lo lejano en lo próximo (Anerkennung von Ferne im Nächsten) se mitiga la extrañeza (Fremdheit); esto es, incorporándola a la conciencia. Pero la pretensión (Anspruch) inderogable de la cercanía perfecta y lograda, la negación misma de la extrañeza, comete con el otro la máxima injusticia, lo niega virtualmente como persona singular, y, por ende, lo humano en él (...) Sólo la más cauta reflexión (behutsamste Reflexion) puede asumir la cuestión de la inmediatez (Der Sache von Unmittelbarkeit) (Adorno, 1998: 182).

Lo "humano" en esta reflexión presenta la exigencia ética de "que todo individuo debe ser respetado como representante de la especie socializada, no como mera función del proceso de canje" (Adorno, 2005: 239).

Retomemos para concluir este apartado la relación entre el impulso de solidaridad que nace ante el sufrimiento del otro y la cuestión del conocimiento en la acción ética. Como decíamos, la decisión es un conocimiento "impulsivo", puesto que la acción no necesita más argumentos que la misma evidencia del hecho al que se refiere. Sin embargo, la falibilidad ética, esto es: el hecho de que el conocimiento situado que implica la decisión no cuenta con garantías para su logro, no significa para Adorno que la conclusión a extraer de la teoría crítica de la moral sea la resignación o el nihilismo. El impulso de solidaridad conduce según Adorno a la formulación de afirmaciones del tipo:

no se torturará; no habrá campos de concentración, mientras todo eso sigue ocurriendo en África y Asia y no se hace más que reprimirlo porque el humanitarismo civilizador es como siempre inhumano con los por él desvergozadamente estigmatizados como incivilizados (Adorno, 2005: 263).

Aun así, en la medida en que la falibilidad es constitutiva de las acciones morales en el capitalismo, estas frases no pueden expresarse positivamente como principios abstractos. De 
otra forma, se estaría desembocando nuevamente en la "mala infinitud" del universalismo moral. En este sentido, "las frases son verdaderas como impulso cuando se anuncia que en algún lugar se ha torturado (...)":

Lo que no pueden es racionalizarse; en cuanto principio abstracto, incurrirían enseguida en la mala infinitud de su deducción y validez. La crítica de la moral va dirigida contra la transposición de la lógica de la consecuencia a la conducta de los hombres; la astringente lógica de la consecuencia se convierte ahí en órgano de la no-libertad (Ibíd:: 263).

Considerado de forma aislada, el impulso somático sería "transformado en un absoluto". Puesto que su destinatario sólo puede ser, como afirma Brecht, un "cuerpo torturable", el impulso inevitablemente plantea una relación entre dos individuos. Por lo tanto, allí donde se abstrae esta experiencia, perdemos de vista las condiciones sociales en las que esa experiencia se vuelve comprensible. En ese sentido, la teoría social crítica de la moral no puede detenerse en "la relación yo-tú" que presupone el concepto de la acción ética; por el contrario, ella "debe ser criticable" (Ibíd.: 273) por su insuficiencia. Si no fuese de este modo, la teoría crítica repetiría la oposición liberal entre lo privado y lo público, que ha cuestionado repetidamente mediante su crítica de la ética de la convicción.

Aquello que permite criticar la relación diádica del yo y del tú es aquello que, precisamente por su ausencia, queda excluido de este binarismo. Nos referimos a la idea de la totalidad social y a la reflexión política que ella reclama. El sufrimiento originado por un agravio de las peticiones de un individuo a su reconocimiento evidencia su insuficiencia allí donde se desgaja de las condiciones que posibilitan o que dificultan no solamente la satisfacción individual sino también el bienestar colectivo. "La emancipación del individuo (...) sería deleznable si no incluyera a toda la humanidad" (Adorno, 1998: 169). Por ello, el impulso de solidaridad de las acciones conscientes da, en términos de Adorno, con una "conciencia paradójica de lo general". La misma consiste en una "cauta reflexión" en la cual lo general asume la contradicción que lo constituye impidiendo su sutura. Paradójicamente, Adorno presenta esta dialéctica entre lo particular y lo general tomando como ejemplo una experiencia que, en principio, se inscribe en la esfera privada; esto es, el amor no correspondido:

En el agraviado (Gekränkten) hay algo que se deja notar con la misma claridad con que los dolores intensos (heftige Schmerzen) iluminan el propio cuerpo (eigenen Leib). (...) El rechazo directo, en el que se impone lo general, le parece al individuo un estado en el que se haya excluido de lo general (...). En el sinsentido de la privación llega a percibir lo falso de toda satisfacción meramente individual. Pero de ese modo se despierta en él la conciencia paradójica de lo general, del inalienable e irrecusable derecho humano a ser amado (...). Con su petición, no fundada en título ni prerrogativa alguna, a ser correspondido apela a una instancia desconocida que con gracia le conceda lo que le pertenece y que no le pertenece. El secreto de la justicia en el amor es la superación del derecho (Aufhebung des Rechts) que el amor reclama en sus gestos mudos (Ibíd:: 165). 


\section{Ideología de la moral}

En este sentido, la teoría social crítica de la moral de Adorno incluye su propia limitación. Parece como si la crítica no pudiese desplegarse completamente si ella no se cuestionase a sí misma desde una perspectiva que le permita ampliar sus propios límites. Esa crítica "exterior" que cuestiona el carácter restrictivo de la perspectiva moral viene dada, según pudimos observar, por las antinomias de la propia experiencia ética. De allí que "la conciencia paradójica de lo general" que se despierta en "lo falso de toda satisfacción meramente individual" es lo que permite entender a la experiencia ética como reflexiva, pues contiene en sí misma a su "otro" que la confronta desde afuera.

Si por un lado el impulso de solidaridad para con el sufrimiento ajeno es la respuesta a las necesidades que el "agraviado" presenta bajo la forma de peticiones singulares de reconocimiento; por otro lado, el respeto por su singularidad no figura, en la modernidad, como la única actitud ética legítima. Del mismo modo en que en estas acciones no interviene la lógica de la forma jurídica, puesto que en ellas se reconoce al otro sin "título ni prerrogativa alguna"; así también, a la inversa, para Adorno las pretensiones de validez contenidas en la forma del derecho deben ser entendidas como una instancia de trascendencia de las lógicas situacionales del impulso, puesto que de lo contrario se desembocaría en una privatización de los conflictos prácticos que deja intactas las condiciones sociales que los originan. Contribuir a la transformación de las condiciones sociales que estructuran distribuciones desiguales de la riqueza social constituye, según la clásica distinción de Horkheimer, aquello que diferencia a la teoría crítica de las perspectivas tradicionales. Y esto también en el caso de la reflexión ética. Si esto no ocurre, dice Adorno, las reflexiones sobre la acción y el conocimiento práctico desembocan en ideología (Adorno, 2003: 164).

Ahora bien, cabe aquí formular las siguientes preguntas: ¿no conducen las reflexiones adornianas sobre los problemas ético-políticos en el mundo contemporáneo a una moralización semejante? ¿Es posible extraer de su teoría crítica del universalismo moral, y con él del principio igualitario, la consecuencia no deseada de una justificación liberal de la desregulación institucional de los vínculos sociales mediados por el mercado capitalista? En último término, ¿no pueden desembocar sus reflexiones en consecuencias antidemocráticas? (Cfr. Geuss, 2005: 128 y ss.) Estas preguntas no pueden responderse sino por medio de una indagación más precisa acerca de lo que significa esta perspectiva exterior para la moral. Presentemos algunas consideraciones preliminares.

Como decíamos, en la teoría crítica de la moral que desarrolla Adorno, es la misma experiencia ética la que conduce, por la auto-reflexión de sus antinomias, hacia una "superación" (Aufhebung). Adorno piensa en esto cuando refiere a una "ampliación a lo político de lo moral" (Adorno, 2003: 164). La experiencia ética cuenta, en la interpretación de Adorno, con su propio remedio frente a los riesgos de devenir ideología: a través del reconocimiento de su dependencia estructural con aquello que se le aparece como exterior. Nos referimos a la cuestión del trato igualitario y de la justicia social.

Adorno analiza lo que denomina el devenir ideología de la moral a partir de la insuficiencia que demuestra el impulso y las virtudes que habían colocado a las prácticas éticas más allá de su fundamentación universalista. A diferencia del proceso de darse a sí mismo 
la ley (Selbstgesetzgebung) con el que Kant identificaba las condiciones subjetivas de una actitud moral universal, las prácticas del regalar o del amar representan instancias en las cuales el individuo se relaciona con una diferencia. Del mismo modo, el impulso mimético con los "cuerpos torturables" asume la posibilidad de actuar éticamente allí donde se asiste al irreductible sufrimiento físico del otro. Sin embargo, el cuestionamiento de la moral racional que sólo se detiene en la idea de un respeto ético del individuo se vuelve radicalmente cuestionable puesto que atiende a las peticiones de reconocimiento de las diferencias en desmedro de la percepción de los fenómenos crecientes de desigualdad social sobre los que se sostiene la vigencia del capitalismo. Su oposición al universalismo igualitarista contenido en la idea de ley moral hace que el impulso

(...) confirme la regla de la inhumanidad mediante la excepción que la pone por obra. Al confiar la superación de la injusticia al amor al prójimo en su contingencia, acepta como inmutable la ley de la alienación universal que quisiera mitigar. Es verdad que el compasivo representa, en cuanto individuo, la pretensión de lo universal, la pretensión de vivir, en contra de lo universal, naturaleza y sociedad, que niegan dicha pretensión. Pero la unidad con lo universal, como lo interior, que el individuo realiza, se revela falaz en la propia debilidad del individuo. No es la blandura, sino la limitación, lo que hace problemática la compasión: ésta es siempre insuficiente. (Adorno y Horkheimer, 1998: 148)

Puesto que el impulso "renuncia a la transformación del todo (...) Contiene un momento de regresión" (Ibíd:: 152). Porque no es posible abstraer la experiencia ética de las condiciones sociales en las que ella se desarrolla -las desigualdades sociales, la explotación de clase- las virtudes determinadas por el impulso de solidaridad, aisladas y convertidas en principios, desembocan en la legitimación ideológica de esas condiciones.

El impulso de solidaridad no discrimina acerca de quién puede devenir objeto de su acción. La identificación mimética que el impulso pone en acto se extiende a cualquier individuo que reaccione contra su padecimiento. Sin embargo, en la medida en que el impulso actúa sobre individuos, no puede realizarse asistiendo a todos al mismo tiempo ni sopesando prioridades. Su aplicación no puede pretender una efectiva universalidad. Por eso el impulso de solidaridad "siempre es insuficiente". Del mismo modo en que el criterio universalista resultaba deficiente para atender a las situaciones concretas en las que la acción se requería de manera inmediata, ahora Adorno presenta el otro lado de la dialéctica práctica de lo general y lo particular, en donde se vuelve legítima la "astringencia" de la "lógica de la consecuencia" que supone la organización del poder político en la forma del derecho.

La fundamentación de una acción o decisión en base a una ley no solamente implica que la norma puede ser aplicada a una variedad múltiple de casos, sino también que su validez puede ser reconocida en principio por cualquiera. La universalidad de la norma implica una idea de igualdad en el trato que atiende a la consideración de todos simultáneamente. Ante la perspectiva normativa de la igualdad, la perspectiva del impulso mimético resulta insuficiente porque se restringe al vínculo con un particular y así "confirma la regla de la inhumanidad mediante la excepción que la pone por obra", vale decir: excluyendo la posibi- 
lidad de atender a las peticiones que el resto de los individuos o grupos presentan con igual derecho. Por el contrario, el principio igualitario posibilita decisiones jurídico-políticas en el sentido de una asimetría que priorice la asistencia de aquellos que, en un conflicto práctico, se encuentran peor posicionados para defender sus derechos.

\section{Conclusiones}

Habiendo transitado por la crítica de la "despractización" a la cual conduce la fundamentación racionalista de la moral, falsearíamos la relación entre ética y política en Adorno si redujésemos uno de los polos al otro. Si en esta concepción aquello que se reconoce es la diferencia entre ambos extremos, esto no niega la posibilidad de interferencias mutuas que dislocan sus pretensiones de clausura e independencia. Las reflexiones éticas y las reflexiones políticas presentan en la teoría social de Adorno un conflicto irresoluble, pues cada una de ellas sólo puede ser pensada en su despliegue a partir del vínculo con aquello que se le contrapone. Para Adorno, un pensamiento y una práctica política orientados en el sentido de la crítica y la emancipación no pueden evitar el tránsito por la experiencia ética, aun cuando se reconozca su precariedad e insuficiencia ante los dilemas de las sociedades tardo-capitalistas.

Esto supone que la experiencia ética no es el único objeto capaz de criticarse a sí mismo. La citada y enigmática noción de una "superación del derecho" (Aufhebung des Rechts) lejos de aludir a alguna versión vernácula de excepcionalismo (Adorno, 2005: 285) invita a pensar que la forma del derecho moderno presenta también una estructura auto-reflexiva (Menke, 2015: 369 y ss.). Una primera forma de interpretar esta reflexividad es en un sentido fuerte, es decir: desde la perspectiva de su disolución o trascendencia. Como hemos podido analizar, en la perspectiva crítica de Adorno la organización jurídica de las relaciones humanas violenta las diferentes formas de vida que no se ajustan a una legislación universal. A la violencia del derecho se le respondería desde la crítica con la exigencia de un pensamiento y una acción que vayan más allá de las abstracciones que someten las singularidades a "la mala infinitud" y "al maldito canje de la compensación” (Adorno, 2005: 294).

Sin embargo, la reflexividad del derecho admite una segunda interpretación. Esta otra lectura viene informada por el reconocimiento de que el proceso de justificación sobre el cual el derecho moderno se sostiene permite atender a las necesidades de protección de aquellos menos favorecidos por las distribuciones desiguales de la riqueza social. De allí que el impulso de solidaridad, limitado al reconocimiento situacional del sufrimiento del otro exija la transición a su contrario, la pretensión legítima de aplicar la norma de manera universal, a los fines de garantizar a todos la asistencia necesaria para explorar los propios objetivos de vida. La reflexividad del derecho entonces implicaría una crítica inmanente sobre sus propios límites para atender a los sufrimientos y a las lesiones de los sujetos sin reproducir la violencia que las origina. En este sentido, una lectura débil de la reflexividad del derecho la interpreta como una preservación transformada o, mejor, como una transformación de aquello que preserva.

Semejante organización (Einrichtung) tendría su telos en la negación del sufrimiento físico (physischen Leidens) aun del último de sus miembros y de las formas interiores de reflexión de ese sufrimiento. Tal es el interés de todos (aller), únicamente realiza- 
ble poco a poco mediante una solidaridad transparente a sí misma y a todo viviente (Adorno, 2005: 190-191).

La tensión que se le aparece a la experiencia entre responder a las peticiones irreductibles de reconocimiento y, al mismo tiempo, extender ese impulso hacia una igualdad en la que todos sean atendidos sin exclusiones, tensión que encuentra su correlato objetivo en los conflictos prácticos del mundo social, es el trasfondo paradójico sobre el que Adorno proyecta el porvenir de un ordenamiento jurídico-político que no violente las relaciones humanas.

Este fondo paradojal incluye un concepto de acción que en la teoría social de Adorno es esbozado, aunque no desarrollado, en su citada exigencia de una politización de la reflexión y la acción éticas. Vale decir, una conceptualización de aquellas prácticas que fuesen capaces de coordinar los vínculos humanos en el sentido de un poder común sin el cual esa transformación del derecho no sería posible. Como Marx, para Adorno el imperativo "de echar por tierra todas aquellas relaciones en que el hombre es un ser humillado, sojuzgado, abandonado y despreciable" (Marx, 1982: 497) sólo puede ser realizado por una politización de la acción y de las relaciones humanas en donde los diferentes momentos de las controversias - la perspectiva evaluativa del individuo y de la sociedad, el impulso mimético y la consideración racional de todos- no sean disueltos en uno de los extremos, sino reconocidos como ineludibles e insuperables. Así, pues, del mismo modo en que la posibilidad de un derecho transformado en su dialéctica con la acción política supone el momento de la reflexión ética sobre la violencia de su forma, así también, la posibilidad de un poder común es necesaria para que el individuo adquiera la fuerza que la acción requiere para diferenciarse de la ideología moral. Sólo así puede no solamente querer lo bueno sino también encontrar la posibilidad de hacerlo.

\section{Bibliografía}

ADORNO, Theodor y HORKHEIMER, Max (1998): Dialéctica de la ilustración, Trotta, Madrid.

ADORNO, Theodor (1963): Probleme der Moralphilosophie, Suhrkamp, Frankfurt.

ADORNO, Theodor (1998): Minima moralia, Madrid, Taurus.

ADORNO, Theodor (2003): Consignas, Buenos Aires, Amorrortu.

ADORNO, Theodor (2005): Dialéctica negativa, Madrid, Akal.

BERNSTEIN, Jay (2001): Adorno: Disenchantment and Ethics, Cambridge, University Press.

BROWN, Wendy (2002): “Suffering the Paradoxes of Law”, en: W. Brown y J. Halley (eds.): Left Legalism/Left Critique, London, Duke University Press.

BUTLER, Judith (2005): Giving an account of oneself, New York, Fordham University Press.

DE VRIES, Hent (1989): Theologie im pianissimo und zwischen Rationalität und Dekonstruktion: Die Aktualität der Denkfiguren Adornos und Levinas, Kampen, Kok.

DERRIDA, Jaques (1998): Políticas de la amistad, Madrid, Trotta.

DÜTTMANN, Alexander (2004): So ist es. Ein philosophischer Kimmentar zu Adornos Minima Moralia, Frankfurt, Suhrkamp. 
GEUSS, Raymond (2005): Outside ethics, Oxford, Princeton University Press.

KANT, Immanuel (2013a): Fundamentación de la metafísica de las costumbres, México D.F., Porrúa.

KANT, Immanuel (2013b): Crítica de la razón práctica, México D.F., Porrúa.

LEVINAS, Emmanuel (2002): Totalidad e infinito, Salamanca, Ediciones Sígueme.

MARX, Karl (1982): Escritos de juventud, México, Fondo de Cultura Económica.

MCDOWELL, John (2002): Mind, value, and reality, Cambridge, Harvard University Press. MENKE, Christoph (2015): Kritik der Rechte, Frankfurt, Suhrkamp.

MENTZ, Paul (2012): Moralphilosophie im Stande der Unfreiheit. Adornos negative Moralphilosophie, Berlin, Helle Panke.

MORRIS, Martin (2001): Rethinking the communicative turn. Adorno, Habermas and the problem of communicative freedom, New York, State University of New York Press.

SCHMID NOERR, Gunzelin (1995): “Adornos Verhältnis zur Mitleidsethik Schopenhauers”, en: Schweppenhäuser, G. y Wischke, M. (Hg.), Impuls und Negativität. Ethik und Ästhetik bei Adorno, Berlin, Argument - Sonderband.

SCHOPENHAUER, Arthur (2009): El mundo como voluntad y representación, Madrid, Trotta.

SCHWEPPENHÄUSER, Gerhard (2006): “Adorno's Negative Moral Philosophy”, en: The Cambridge Companion to Adorno, Cambridge, Cambridge University Press.

TAYLOR, Charles (1985) Philosophy and the Human Sciences: Philosophical Papers II, Cambridge, Cambridge University Press.

WISCHKE, Mirko (1993): Kritik der Ethik des Gehorsams. Zum Moralproblem bei Theodor W. Adorno, Frankfurt, Peter Lang. 